\title{
Surfing through the coating system of historic bowed instruments: perspective
}

\author{
Giacomo Fiocco, ${ }^{\text {a,b }}$ Claudia Invernizzi, a,c Tommaso Rovetta, ${ }^{a}$ Michela Albano, ${ }^{a, d}$ \\ Marco Malagodi, ${ }^{\text {a,e }}$ Patrizia Davit ${ }^{b}$ and Monica Gulmini ${ }^{b}$ \\ aLaboratorio Arvedi di Diagnostica Non Invasiva, CISRiC, Università degli Studi di Pavia, Via Bell'Aspa 3, 26100 \\ Cremona, Italy \\ bDipartimento di Chimica, Università di Torino, Via Pietro Giuria 7, 10125, Torino, Italy \\ 'Dipartimento di Scienze Matematiche, Fisiche e Informatiche, Università degli Studi di Parma, Parco Area delle Scienze, \\ 7/A, 43124 Parma, Italy \\ 'Dipartimento di Fisica, Politecnico di Milano, Piazza Leonardo da Vinci 32, 20133, Milano, Italy \\ eDipartimento di Musicologia e Beni Culturali, Università degli Studi di Pavia, Corso Garibaldi 178, 26100 Cremona, \\ Italy
}

Which materials did the great Cremonese violin makers use to coat their violins? Is it possible to determine the secret recipes jealously guarded by the luthiers in their workshops? Although almost three centuries have passed since his death, the myth of Antonio Stradivari still represents the epitome of violin making. Indeed, every violin maker has the ambition, more or less declared openly, to build instruments similar to those produced in the Cremonese workshops in the $17^{\text {th }}$ and $18^{\text {th }}$ centuries. Stradivari lived for 93 years and after his death Cremonese violin making progressively decreased in quality and quantity. This decline has inevitably led to the loss of traditions and knowledge, creating a deep gap between historical and contemporary lutherie. Since the second

\section{DOI: $10.1255 /$ sew.2021.a8}

(C) 2021 The Authors

Published under a Creative Commons BY-NC-ND licence

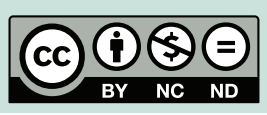

half of the $20^{\text {th }}$ century, however, luthiers who aspired to be scientists and scientists with a passion for musical instruments proposed more or less convincing hypotheses concerning the materials used by the great masters. ' Only in the last few decades has scientists' interest in musical instruments grown, and the increasing historic (and economic) importance of ancient violins has fuelled the scientific debate on how to approach the investigation. Technical peculiarities of these artworks have been studied, 2,3 with the main focus on the nature of the fine Cremonese varnish and of the other materials involved in the overall finishing treatment. ${ }^{4}$

It is known that multiple varnish layers were applied to the wood, which had been pre-treated with a sealer to prevent varnish penetration. In addition, $\mu \mathrm{m}$-sized inorganic particles are sometimes dispersed in the coating system. The most common materials involved in the finishing processes were siccative oils, natural resins, casein or animal glues, inorganic fillers, organic and inorganic colourants. ${ }^{5}$ Furthermore, other substances such as benzoin or shellac resin were commonly used on ancient violins-and still are in contemporary ones-as surface polishes for conservation, restoration and maintenance. ${ }^{6}$

Despite some similarities with other painting techniques, the finishing of wooden, bowed string instruments has peculiar purposes and characteristics. In particular, the varnish must not only be a protective layer, but it should be coloured, transparent and glossy, in order to enhance the wood features. A number of colourants (pigments, lakes or dyes), normally spread at very low concentration, or specific pre-treatments can be employed to obtain the typical shades of the varnish.

Spectroscopies based on infrared radiation and $\mathrm{X}$-rays are perfect candidates for the study of these materials as they enable the identification of both organic and inorganic chemical species.

Fourier transform infrared (FT-IR) spectroscopy specifically identifies the functional groups mainly related to the organic materials and to some inorganic components (e.g. carbonates, silicates, sulphates) of the layers. As for bowed string musical instruments, where sampling is often impossible, the use of portable non-invasive reflection 
FT-IR spectroscopy may be necessary to collect chemical information. A tentative non-invasive stratigraphic approach-that considers spectra obtained by analysing differently preserved varnish areas-can be successful using this technique. ${ }^{6}$ On the other hand, FT-IR micro-spectroscopy can be exploited for investigating embedded samples prepared as cross-sections. In this way, the stratigraphy can be observed and analysed layer-by-layer. ${ }^{7}$

As for the characterisation of the elemental composition of the inorganic materials dispersed in the coating system, X-ray-based techniques represent the first choice among the set of analytical options. X-ray fluorescence (XRF) spectroscopy characterises the elemental composition in a volume of material without the need to take samples. For this reason, XRF is one of the most widely used techniques for detecting pigments and other inorganic materials in the cultural heritage field. ${ }^{8}$ In the investigation of musical string instruments, the entire volume of the system (coatings and wood) is involved in the analytical spot, from the external dirt deposits to the inorganic-based treatments of the wood. ${ }^{9}$

On the other hand, scanning electron microscopy coupled to energy-dispersive $X$-ray spectroscopy (SEM-EDX) enables the analyses of micrometric spots in each layer of the stratigraphy, ${ }^{4}$ provided that a micro-sample is detached from the instrument.

Over the years, other spectroscopic techniques have been used to scrutinise the finishing layers of musical instruments: laser induced breakdown spectroscopy (LIBS) has been employed to obtain the sub-surface stratigraphy with a micro-destructive approach; ${ }^{10}$ nuclear magnetic resonance (NMR) and Raman spectroscopy ${ }^{11}$ provided valuable data for in-depth understanding of materials and the construction techniques of the historical Cremonese violins, although information is more difficult to obtain with these techniques. The results related to all the above-mentioned spectroscopic approaches are well described in the references cited in this article.

Here, the Bracco 1793 small violin made by Lorenzo Storioni (1744-1816) in Cremona, Italy is reported as a representative case study (Figure 1a). The instrument has been subjected to a multi-analytical procedure exploiting $X$-rays and IR radiation employed according to non-invasive and micro-invasive approaches.

\section{FT-IR spectroscopy in reflection geometry}

The non-invasive FT-IR data were collected with a Bruker Alpha portable spectrometer on some spots of the soundboard and backplate selected on the basis of the ultraviolet fluorescence response and the different levels of wear of the varnish. In addition, synchrotron radiation (SR)-FT-IR was performed at the SISSI beamline of Sincrotrone Elettra Trieste, with the valuable support of Dr L. Vaccari and Dr C. Stani. Here, a sample was detached from a representative area of the soundboard (Figure 1b), embedded into epoxy resin and treated to expose a polished cross-section (Figure 1c). SR brightness and lateral resolution lead to spectra with improved signal-tonoise ratios. Both the approaches, i.e. non-invasive with a portable instrument and micro-invasive at a large-scale facility, were carried out in reflection geometry.

The spectra collected through the noninvasive approach on the varnished areas mainly highlighted the signals of a resinous varnish at around $1710 \mathrm{~cm}^{-1}(\nu \mathrm{C}=\mathrm{O})$ (Figure 2a). In order to characterise the preparation layers, often spread on the wood to avoid the penetration of the varnish into the wood pores, the analyses were also focused on some worn areas of the soundboard or backplate, where the varnish is no longer identifiable. In these areas, the spectra (Figure 2b) suggested the presence of a proteinaceous ground coat $^{12}$ as a shoulder at

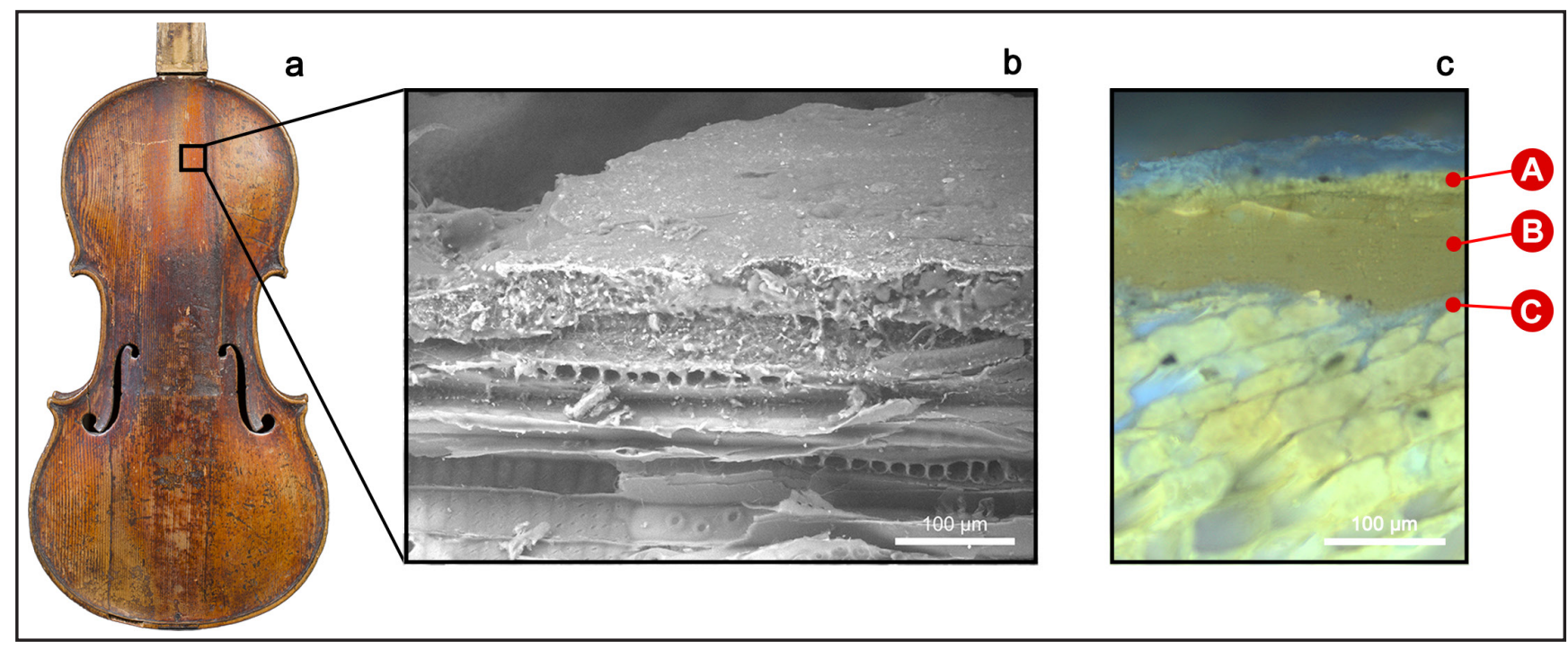

Figure 1. (a) Visible image of the soundboard of the Bracco 1793 small violin. The sampling spot is marked by the black square. The detached micro-sample observed through the (b) SEM (backscattered electron image) and (c) the optical microscope under ultraviolet (UV) light. The finishing treatments $(A, B, C)$ are visible on the wood substrate. 
$1650 \mathrm{~cm}^{-1}(\nu \mathrm{C}=\mathrm{O}$, amide $\mathrm{I})$ and a broad band at $1550 \mathrm{~cm}^{-1}$ (combination of $\nu \mathrm{C}-\mathrm{N}$ and $\delta \mathrm{N}-\mathrm{H}$, amide II) were present. In addition, inorganic compounds-probably dispersed in the layers or dry-filled directly in the wood pores-were also detected: the Reststrahlen bands at around $1100-1000 \mathrm{~cm}^{-1}$ ( $\nu_{\text {as }} \mathrm{Si}-\mathrm{O}-\mathrm{Si}$ ) can be attributed to the silicate group. Signals of the sulphate group at 1150 and $1100 \mathrm{~cm}^{-1}\left(\nu_{\text {as }} \mathrm{SO}_{4}\right)$, and at 670 and $600 \mathrm{~cm}^{-1}\left(\delta_{\mathrm{as}} \mathrm{SO}_{4}\right)$ were also observed. ${ }^{13}$

The micro-invasive analysis carried out on the cross-section shown in Figure 1c, allowed us to deepen our knowledge of the sequence of the organic layers. SR-FTIR spectra collected on layers $A$ and $B$ (Figure $3 a, b$ ) clearly confirm the presence of the marker bands of natural terpenic resins ${ }^{11}$ mainly for the intense $\nu \mathrm{C}=\mathrm{O}$ band approximately at $1710 \mathrm{~cm}^{-1}$ ascribable to the carboxylic acid contribution, the $\delta_{\mathrm{s}} \mathrm{CH}_{2}$ and $\delta_{\mathrm{as}} \mathrm{CH}_{3}$ at $1450 \mathrm{~cm}^{-1}$, $\delta_{\mathrm{s}} \mathrm{CH}_{3}$ around $1375 \mathrm{~cm}^{-1}$ and $\nu \mathrm{C}-\mathrm{O}$ at 1255 and $1185 \mathrm{~cm}^{-1} .^{14}$ Spectra collected on layer C (Figure 3c) are instead characterised by bands related to proteinaceous materials-such as animal glue or casein-at $1650 \mathrm{~cm}^{-1}$ and $1550 \mathrm{~cm}^{-1}$.

\section{Investigation of the inorganic phases by X-rays}

For the non-invasive approach, the XRF analysis was performed with a Bruker XG Lab Elio portable spectrometer on different areas carefully selected on the basis both on the ultraviolet fluorescence response and on the different levels of wear of the varnish. SEM-EDX micro-analyses were carried out on the embedded sample detached from the soundboard with a Tescan Mira 3XMU-series equipped with an energydispersive $\mathrm{X}$-ray spectrometer.

XRF data obtained by the non-invasive approach revealed the presence of $\mathrm{Si}, \mathrm{S}, \mathrm{K}, \mathrm{Ca}$ and Fe both on the soundboard and the backplate. The detection of silicon in the worn areas, as well as

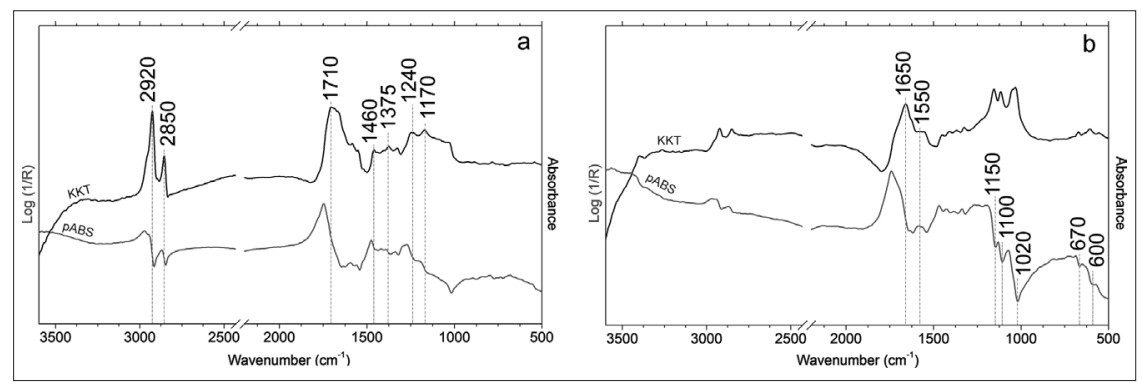

Figure 2. Reflection FT-IR spectra acquired on the varnished (a) and most worn (b) areas of the Bracco 1793 small violin in pseudo-absorbance (PABS) and after Kramers-Krönig transformation (KKT). The marker bands are reported. Reprinted with permission from Reference 7.

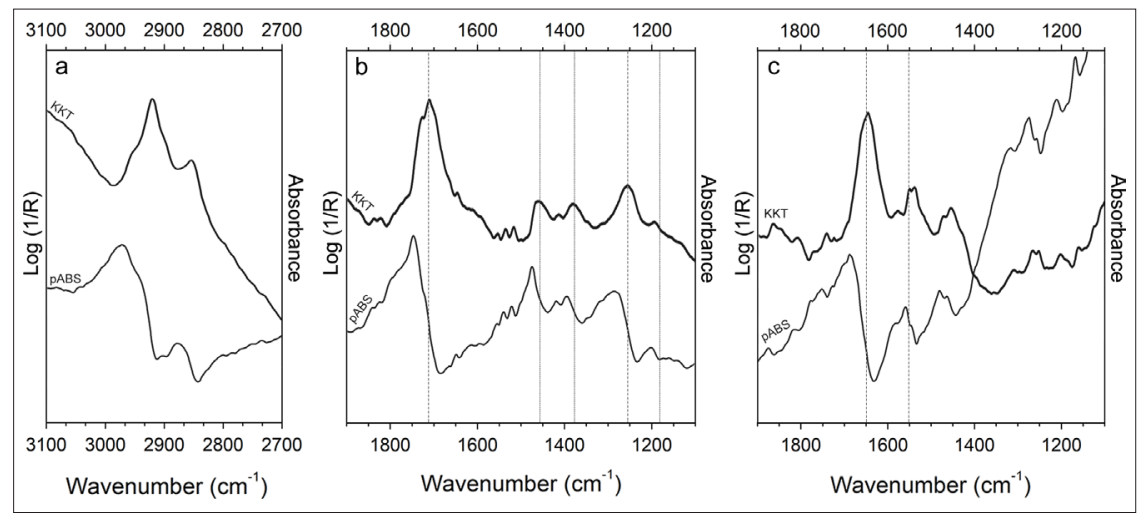

Figure 3. Reflection SR-FT-IR spectra in pseudo-absorbance (pABS) and after KKT corresponding to layer $B(a, b)$ and $C(c)$. Marker bands are reported. Reprinted with permission from Reference 7.

the higher counts of calcium and sulphur, can be attributed to the presence of these inorganic phases, acting as fillers at the ground level, further supporting the information obtained through nonand micro-invasive FT-IR. The EDX microanalysis partially confirms these results: Si- and Ca-based particles were detected in layer $\mathrm{C}$, clearly identifying the presence of an inorganic dispersion in the proteinaceous layer spread on the wood. The presence of iron, identified both with XRF and EDX, was instead attributed to iron earth particles, possibly added as pigments. 6,15

\section{Conclusions and outlook}

Techniques based on IR and X-ray spectroscopies normally allow the identification and characterisation of most of the variety of materials involved in the finishing processes of historical violins, with the Lorenzo Storioni Bracco small violin made in 1793 in Cremona discussed here as a relevant example of a comprehensive spectroscopic approach.

$X$-rays and IR spectroscopies revealed the presence of a natural resin-based varnish, in accordance with those identified on other historical Cremonese string instruments from the $17^{\text {th }}$ and $18^{\text {th }}$ century, and suggesting a remarkable consistency in the materials and procedures employed by the great masters to obtain the finishing layers over almost 150 years. A proteinaceous ground layer with a dispersion of some silicate- and sulphate-based particles, and the presence of small red earth particles were also detected in the stratigraphy.

In the future, it is expected that spectroscopic techniques will be extensively employed for the investigation of luthiers' secrets, with further stringed instruments being investigated. Radiation from X-rays to IR is leading research towards a deeper knowledge of the large variety of materials, often mixed together, employed by the luthiers.

\section{Acknowledgements}

The authors acknowledge the Fondazione Arvedi-Buschini, the Fondazione Bracco and the Fondazione Museo del Violino for support. Special thanks to Dr Lisa 
Vaccari and Dr Chiaramaria Stani for their assistance at the SISSI beamline.

\section{References}

1. J. Michelman, Violin Varnish: A Plausible Re-Creation of the Varnish Used by the Italian Violin Makers Between the Years 1550 and 1750. J. Michelman (1946).

2. B.H. Tai, "Stradivari's varnish. A review of scientific findings-part I", J. Violin. Soc. Am. 21, 1 (2007).

3. C. Invernizzi, A. Daveri, T. Rovetta, M. Vagnini, M. Licchelli, F. Cacciatori and M. Malagodi, "A multi-analytical noninvasive approach to violin materials: the case of Antonio Stradivari 'Hellier' (1679)", Microchem. J. 124, 743-750 (2016). https://doi.org/10.1016/j. microc.2015.10.016

4. G. Fiocco, T. Rovetta, M. Gulmini, A. Piccirillo, M. Licchelli and $M$. Malagodi, "Spectroscopic analysis to characterize finishing treatments of ancient bowed string instruments", Appl. Spectrosc. 71, 2477-2487 (2017). https://doi. org/10.1177/0003702817715622

5. V. Bucur, Handbook of Materials for String Musical Instruments. Springer International Publishing (2016). https://doi.org/10.1007/978-3-31932080-9

6. C. Invernizzi, G. Fiocco, M. Iwanicka, M. Kowalska, P. Targowski, B. Blümich, C. Rehorn, V. Gabrielli, D. Bersani, M. Licchelli and M. Malagodi, "Non-invasive mobile technology to study the stratigraphy of ancient Cremonese violins: OCT, NMR-MOUSE, XRF and reflection FT-IR spectroscopy", Microchem. J. 155, 104754 (2020). https://doi. org/10.1016/j.microc.2020.104754

7. G. Fiocco, C. Invernizzi, S. Grassi, P. Davit, M. Albano, T. Rovetta, C. Stani, L. Vaccari, M. Malagodi, M. Licchelli and M. Gulmini, "Reflection FTIR spectroscopy for the study of historical bowed string instruments: Invasive and non-invasive approaches", Spectrochim. Acta A 245, 118926 (2021). https://doi. org/10.1016/i.saa.2020.118926

8. S. Ridolfi, "Portable X-ray fluorescence spectrometry for the analyses of cultural heritage", IOP Conf. Ser.: Mater. Sci. Eng. 37, 012001 (2012). https://doi.org/10.1088/1757899X/37/1/012001

9. F. Caruso, S. Saverwyns, M. Van Bos, D.F. Chillura Martino, A.E. Ceulemans, J. Valck and E. Caponetti, "Micro-X-Ray fluorescence and the old masters", Appl. Phys. A 107, 197-202 (2011). https://doi.org/10.1007/s00339011-6729-x

10. F. Poggialini, G. Fiocco, B. Campanella, S. Legnaioli, V. Palleschi, M. Iwanicka, P. Targowski, M. Sylwestrzak, C. Invernizzi, T. Rovetta, M. Albano and M. Malagodi, "Stratigraphic analysis of historical wooden samples from ancient bowed string instruments by laser induced breakdown spectroscopy", J. Cult. Herit. 44, 275-284 (2020). https://doi.org/10.1016/j. culher.2020.01.011
11. C. Daher, C. Paris, A.S. Le Hô, L. Bellot-Gurlet and J.P. Échard, "A joint use of Raman and infrared spectroscopies for the identification of natural organic media used in ancient varnishes", J. Raman Spectrosc. 41, 1494-1499 (2010). https://doi. org/10.1002/jrs.2693

12. K. Belbachir, R. Noreen, G. Gouspillou and C. Petibois, "Collagen types analysis and differentiation by FTIR spectroscopy", Anal. Bioanal. Chem. 395, 829-837 (2009). https://doi. org/10.1007/s00216-009-3019-y

13. C. Miliani, F. Rosi, A. Daveri and B.G. Brunetti, "Reflection infrared spectroscopy for the non-invasive in situ study of artists' pigments", Appl. Phys. A 106, 295-307 (2011). https://doi. org/10.1007/s00339-011-6708-2

14. C. Invernizzi, A. Daveri, M. Vagnini and M. Malagodi, "Non-invasive identification of organic materials in historical stringed musical instruments by reflection infrared spectroscopy: a methodological approach", Anal. Bioanal. Chem. 409, 3281-3288 (2017). https://doi.org/10.1007/ s00216-017-0296-8

15. T. Rovetta, C. Invernizzi, M. Licchelli, F. Cacciatori and M. Malagodi, "The elemental composition of Stradivari's musical instruments: new results through non-invasive EDXRF analysis", X-Ray Spectrom. 47, 159-170 (2018). https://doi.org/10.1002/ xrs. 2825



Giacomo Fiocco has been a research fellow at the Arvedi Laboratory of non-Invasive Diagnostics of the University of Pavia since 2016. In 2018 he started his PhD in Chemistry and Materials Sciences at the University of Turin with a project on the characterisation of the materials used in violin making for the colouring of stringed instruments. (D) https://orcid.org/0000-0002-1458-9640 giacomo.fiocco@unipv.it 


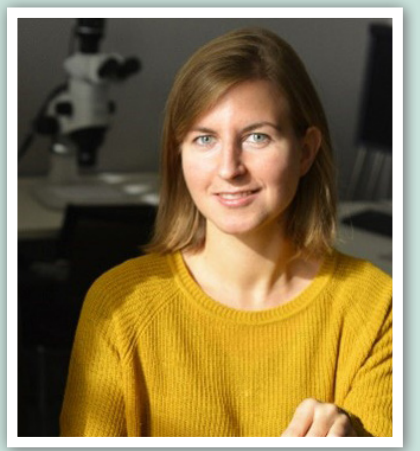

Claudia Invernizzi is a research fellow at the Arvedi Laboratory of Non-Invasive Diagnostics, University of Pavia. Her PhD degree in Physics at the University of Parma focused on the study of the microscopic layered structures of musical instruments by advanced multi-analytical methods. Since 2013, she has specialised in reflection FT-IR spectroscopy (specular, diffuse, ATR, transflection).

(i) https://orcid.org/0000-0001-5111-6589 claudia.invernizzi@unipv.it



Tommaso Rovetta is a conservation scientist and fellow of the University of Pavia in Cremona. He specialises in the analysis of the materials of ancient musical instruments through imaging techniques and X-ray fluorescence spectroscopy. Tommaso is also a violin maker and teaching coordinator of the Accademia Liuteria Piemontese San Filippo of Turin.

(iD) https://orcid.org/0000-0002-9626-8380 tommaso.rovetta@unipv.it

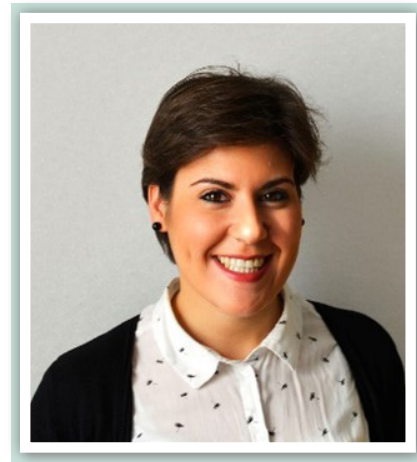

Michela Albano is a research fellow at the Arvedi Laboratory of Non-Invasive Diagnostics, University of Pavia, and a PhD student at the Polytechnic of Milan. Her research activity is focused on the characterisation of materials and procedures in the making of historical musical instruments exploiting imaging and spectroscopic techniques.

(iD) https://orcid.org/0000-0001-5129-9434 michela.albano@unipv.it

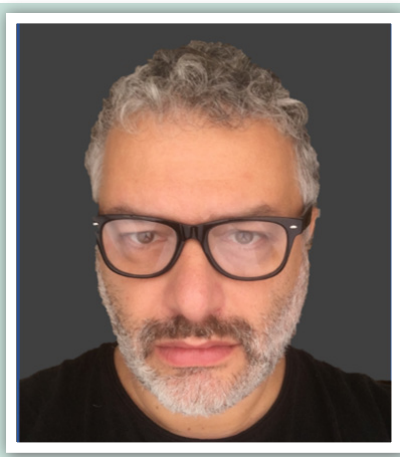

Marco Malagodi is Associate Professor of Chemistry for Cultural Heritage at University of Pavia. Malagodi is the Scientific Head of Arvedi Laboratory of nonInvasive Diagnostics for the study of historical music instruments. The research activities are focused on the characterisations of materials used during the construction procedures of musical instruments.

(D) https://orcid.org/0000-0003-4286-6331 marco.malagodi@unipv.it 


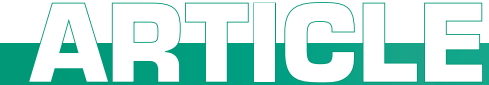



Patrizia Davit is a research technician at the Chemistry Department of Torino University. Her research activities are devoted to the characterisation, evaluation of the technology of production, provenance studies and analysis of degradation phenomena of archaeological, historical and artistic materials. (iD https://orcid.org/0000-0002-9073-9858 patrizia.davit@unito.it

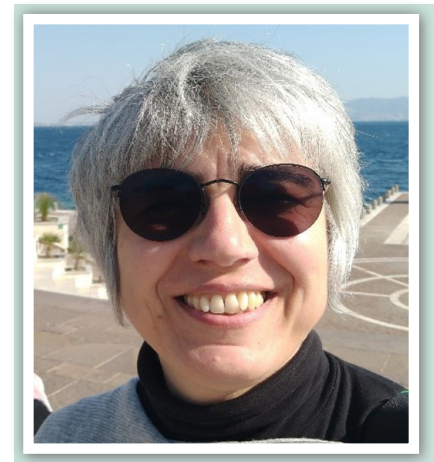

Monica Gulmini serves as a research associate in Analytical Chemistry at the Department of Chemistry (University of Torino - Italy) and leads the team ArchaeoMetry and Analytical cheMistry in Art, hiStory and Archaeology (AMAMASA). Her activity focuses on scientific investigations of archaeological finds and artworks aimed at deepen our knowledge on tangible cultural heritage.

(i) https://orcid.org/0000-0002-0556-5401

monica.gulmini@unito.it

"...every violin maker has the ambition ... to build instruments similar to those produced in the Cremonese workshops in the $17^{\text {th }}$ and $18^{\text {th }}$ centuries"

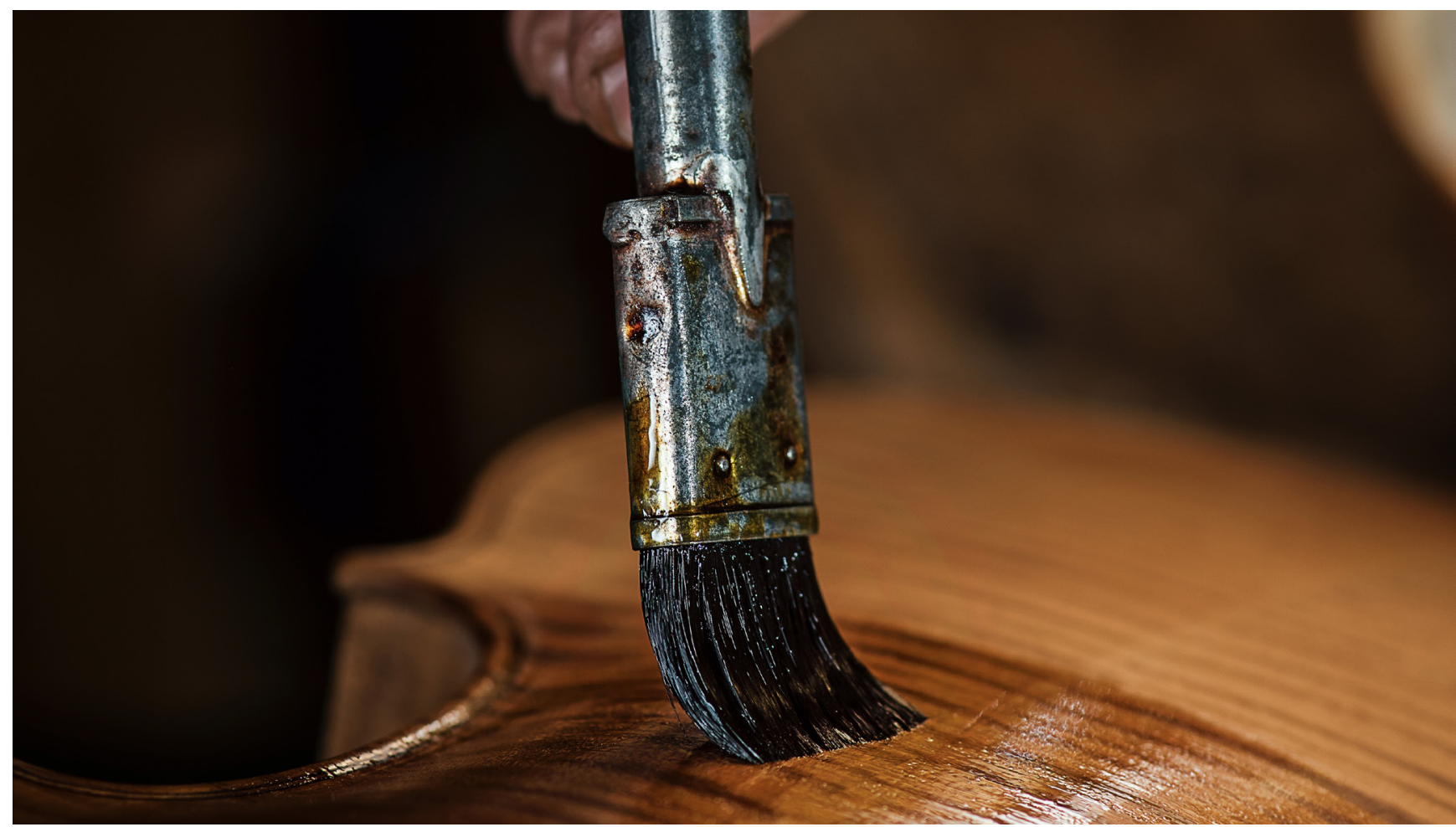

